\title{
Pharmacokinetic study of once-daily versus twice-daily abacavir and lamivudine in HIV type-1-infected children aged 3-<36 months
}

\author{
Paediatric European Network for Treatment of AIDS (PENTA) ${ }^{\star}, \dagger$
}

\section{Abstract}

Background-Once-daily dosing of abacavir and lamivudine has been approved for adults, but paediatric data are insufficient. We conducted a pharmacokinetic study of once-daily and twicedaily abacavir and lamivudine in children aged 3-<36 months.

Methods-Children with stable HIV type-1 (HIV-1) RNA levels after 12 weeks treatment with twice-daily abacavir $(8 \mathrm{mg} / \mathrm{kg})$ with or without lamivudine $(4 \mathrm{mg} / \mathrm{kg})$ underwent plasma pharmacokinetic sampling. Children then switched to once-daily abacavir $(16 \mathrm{mg} / \mathrm{kg})$ with or without lamivudine $(8 \mathrm{mg} / \mathrm{kg})$, and sampling was repeated 4 weeks later. The area under the plasma concentration-time curve over $24 \mathrm{~h}\left(\mathrm{AUC}_{0-24}\right)$ and the maximum concentration $\left(\mathrm{C}_{\max }\right)$ were compared using geometric mean ratios (GMRs); $90 \%$ confidence intervals (CIs) within the range of $0.80-1.25$ were considered bioequivalent.

Results-A total of 18 children $(4,6$ and 8 in the $3-<12,12-<24$ and $24-<36$ month age ranges, respectively) provided pharmacokinetic data for abacavir (17 for lamivudine). The GMR of $\mathrm{AUC}_{0-24}$, once-daily versus twice-daily, was 1.07 (90\% CI 0.92-1.23) for abacavir and 0.91 (90\% CI 0.79-1.06) for lamivudine. $\mathrm{C}_{\max }$ almost doubled on once-daily versus twice-daily dosing: abacavir and lamivudine GMRs were 2.04 (90\% CI 1.73-2.42) and 1.78 (90\% CI 1.52-2.09), respectively. At baseline, 12, 24 and 48 weeks, $89 \%, 94 \%, 100 \%$ and $89 \%$ of children had HIV-1 RNA $<400$ copies/ml, respectively.

Conclusions-Bioequivalence was demonstrated on $\mathrm{AUC}_{0-24}$ between twice-daily and oncedaily abacavir; very similar $\mathrm{AUC}_{0-24}$ values were seen for twice-daily and once-daily lamivudine. Given that viral load suppression rates were maintained, these data suggest that once-daily abacavir and lamivudine might be an option for children aged 3-<36 months.

\section{Introduction}

AIDS-related mortality and morbidity has decreased substantially since the introduction of combination antiretroviral therapy (ART) in HIV-infected children [1,2]; however, long-

\section{(C)2010 International Medical Press}

*Corresponding author penta@ctu.mrc.ac.uk.

†The writing committee is listed at the end of the article and a full list of all PENTA-associated committees can be found via Additional file 1

Writing committee Evelyne Jacqz-Aigrain, Linda Harrison, Wei Zhao, Alexandra Compagnucci, Hannah Castro (née Green), Laura Farrelly, Yacine Saidi, Djamel Hamadache, Steven Welch, Uwe Wintergerst, Silvia Forcat, Ghenima Hadjou, Ghislaine Firtion, Wendy Snowden, Carlo Giaquinto, Diana Gibb and David Burger.

Disclosure statement WS declares a financial conflict of interest as a result of affiliation with GlaxoSmithKline. All other members of the writing committee declare no competing interests.

Additional file Additional file 1: A full list of all PENTA-associated comittees can be found at http://www.intmedpress.com/uploads/ documents/AVT-09-OA-1392_Harrison_(PENTA_Group)_Add_file1.pdf 
term therapeutic success depends on good adherence [3-6]. Adherence is related to several factors, including volume and palatability of medication, the complexity of medication schedules and interference with daily activities [6-9]. In adults, once-daily medication has been shown to enhance adherence and patient satisfaction with ART [10-13]. Good adherence and acceptability to once-daily ART has also been reported in children [14].

Abacavir and lamivudine have been approved for once-daily dosing for adults $[15,16]$. PENTA 13, a pharmacokinetic (PK) study performed in HIV type-1 (HIV-1)-infected children aged 2-13 years, showed that abacavir and lamivudine taken once-daily were well tolerated and non-inferior in terms of PK profiles and continued HIV-1 RNA suppression, compared with corresponding twice-daily regimens [17]. However, only three children under 3 years of age were included. Very young children have a fluctuating gastrointestinal absorption rate, a larger volume of distribution for water-soluble drugs and faster renal clearance per kg body weight (the latter being the principal route of elimination for both lamivudine and abacavir metabolites); therefore, it might not be appropriate to extrapolate the findings of PENTA 13 to infants and younger children [16,18-20].

PENTA 15 (trial number ISRCTN38147516) was a multicentre, open-label, within-child, crossover PK study in HIV-1-infected children aged 3-<36 months. The aim of the study was to compare plasma PK parameters of once-daily versus twice-daily dosing of abacavir and lamivudine. Secondary objectives were to describe age-related differences in once-daily versus twice-daily PK parameters in three age groups (3-<12, 12-<24 and 24-<36 months), and to describe child and family acceptability of (and adherence to) once-daily compared with twice-daily dosage regimens.

\section{Methods}

\section{Study population}

HIV-1-infected children aged 3-<36 months taking twice-daily abacavir (Ziagen®; GlaxoSmithKline, Research Triangle Park, NC, USA) with or without twice-daily lamivudine (Epivir®; GlaxoSmithKline), both as oral solutions for at least 12 weeks as part of combination ART, were included. HIV-1 RNA levels were required to be either $<400$ copies $/ \mathrm{ml}$ or if $\geq 400$ copies $/ \mathrm{ml}$ to be stable or decreasing and $<20,000$ copies $/ \mathrm{ml}$, with no plans to change medication in the next 12 weeks. Likewise, the percentage of $\mathrm{CD}^{+} \mathrm{T}$-cells was required to be stable or rising prior to entry. Children were excluded if they had an intercurrent illness, were receiving concomitant therapy except prophylactic antibiotics or had abnormal renal or liver function (grade 23 ). The protocol was approved by the ethics committee for each participating centre. All parents/guardians provided written informed consent.

\section{Study design}

At week 0 , children on twice-daily abacavir $8 \mathrm{mg} / \mathrm{kg}$ (with or without twice-daily lamivudine $4 \mathrm{mg} / \mathrm{kg}$ ) had blood samples taken at 0 (pre-dose), 1, 2, 3, 4, 6, 8 and $12 \mathrm{~h}$ after observed intake of medication. Children then switched to once-daily abacavir $16 \mathrm{mg} / \mathrm{kg}$ (and once-daily lamivudine $8 \mathrm{mg} / \mathrm{kg}$ if applicable). The same total daily dose of both drugs was given. Children took once-daily medication in the morning until the week 4 visit when a second PK sampling (at 0 [pre-dose], 1, 2, 3, 4, 6, 8, 12 and $24 \mathrm{~h}$ ) was performed. Children were subsequently followed until week 48 , with the intention for all to remain on once-daily abacavir (with or without once-daily lamivudine) at least until week 12 . Switch back to twice-daily dosing was at the discretion of the physician and family. After week 4, oncedaily medication dosing could be changed from the morning to a different, but regular, time 
of day. Carers were asked to complete questionnaires on adherence to ART (week 0, 4 and 12) and on acceptability of once-daily dosing (week 0 and 12).

\section{Pharmacokinetic analyses}

Plasma concentrations of abacavir and lamivudine were determined by a validated HPLC assay with ultraviolet detection at a wavelength of $260 \mathrm{~nm}$; measurements were performed at the Department of Pediatric Pharmacology and Pharmacogenetics (Clinical Investigation Center CIC Inserm 9202, Hôpital Robert Debré, Paris, France). Methods were crossvalidated with the Department of Clinical Pharmacy of the Radboud University Nijmegen Medical Center (Nijmegen, the Netherlands), where the assay was developed [21]. The lower limit of quantification (LLQ) was $0.015 \mathrm{mg} / \mathrm{l}$ for both abacavir and lamivudine. PK parameters (area under the plasma concentration-time curve $\left[\mathrm{AUC}_{0-\mathrm{T}}\right.$, h•mg/l], apparent oral clearance relative to body weight $[\mathrm{CL} / \mathrm{F} / \mathrm{kg}, 1 /(\mathrm{h} \bullet \mathrm{kg})]$, maximum plasma concentration $\left[\mathrm{C}_{\max }, \mathrm{mg} / \mathrm{l}\right]$; minimum plasma concentration $\left[\mathrm{C}_{\min }, \mathrm{mg} / \mathrm{l}\right]$ and elimination half-life $\left[\mathrm{t}_{1 / 2}, \mathrm{~h}\right]$ ) were calculated using non-compartmental methods and the linear up/log down trapezoidal procedure within WinNonlin version 5.2 (Pharsight Corporation; Mountain View, CA, USA). The options 'uniform weighting' and 'best-fit' were used and concentrations below LLQ were set to ' 0 ' (when it appeared in the absorption phase) or 'missing' (when it appeared in the elimination phase). For $\mathrm{AUC}_{0-\mathrm{T}}$, $\mathrm{T}$ was $12 \mathrm{~h}$ for twice-daily and $24 \mathrm{~h}$ for once-daily dosing. Daily AUC ( $\left.\mathrm{AUC}_{0-24}\right)$ was estimated for the twice-daily regimen by calculating $\mathrm{AUC}_{0-24}=2 \times \mathrm{AUC}_{0-\mathrm{T}}$.

\section{Sample size}

Target enrolment was 18 children, 6 in each age group: $3-<12,12-<24$ and $24-<36$ months. If a child did not complete both PK evaluation days on twice-daily and once-daily regimens, their data was not evaluable for the purposes of the study and an additional child in the relevant age group was recruited as a replacement. On the basis of plasma abacavir PK data from the PENTA 13 study [17], the standard deviation of change in $\log _{10}\left(\mathrm{AUC}_{0-24}\right)$ between twice-daily and once-daily dosing was approximately $0.13 \log _{10}(\mathrm{~h} \bullet \mathrm{mg} / \mathrm{l})$. Eighteen children providing plasma abacavir PK data on both twice-daily and once-daily regimens was expected to provide at least $80 \%$ power for the width of the $90 \%$ confidence interval (CI) for the mean $\log _{10}\left(\mathrm{AUC}_{0-24}\right)$ difference between twice-daily and once-daily to be $<0.113$. For example, the $90 \% \mathrm{CI}$ for a ratio of geometric mean $\mathrm{AUC}_{0-24}$ of 1.00 (no difference between twice-daily and once-daily $\mathrm{AUC}_{0-24}$ observed) would be 0.88-1.14.

\section{Statistical analyses}

Statistical calculations were performed using Stata version 10 (StataCorp LP, College Station, TX, USA). For each child, ratios of $\mathrm{AUC}_{0-24}, \mathrm{CL} / \mathrm{F} / \mathrm{kg}$ and $\mathrm{C}_{\max }$ for once-daily versus twice-daily were calculated. Overall geometric mean ratios (GMRs) were calculated after $\log _{10}$ transformation of the within-patient ratios. For $\mathrm{AUC}_{0-24}$ and $\mathrm{CL} / \mathrm{F} / \mathrm{kg}$, a GMR with $90 \% \mathrm{CI}$ including 1.00 and falling entirely within the range $0.80-1.25$ was considered bioequivalent. In each age group $(3-<12,12-<24$ and $24-<36$ months), geometric means (GMs) were calculated separately for twice-daily and once-daily; GMRs were calculated for once-daily versus twice-daily. Data were compared with published results from steady-state PK studies in children using $8 \mathrm{mg} / \mathrm{kg}$ twice-daily or $16 \mathrm{mg} / \mathrm{kg}$ once-daily abacavir and $4 \mathrm{mg} /$ $\mathrm{kg}$ twice-daily or $8 \mathrm{mg} / \mathrm{kg}$ once-daily lamivudine (tablets and oral solution; PENTA 13 [17]); comparisons were also made with adults using $300 \mathrm{mg}$ twice-daily or $600 \mathrm{mg}$ oncedaily abacavir tablets (CAL102120 [22]) and $150 \mathrm{mg}$ twice-daily or $300 \mathrm{mg}$ once-daily lamivudine tablets (EPV1001 [23]). Major resistance mutations were defined according to the 2008 International AIDS Society-USA guidelines [24]. 


\section{Results}

A total of 18 children, enrolled between July 2006 and May 2008, had two evaluable PK days and were included in all main analyses (Figure 1). Safety and efficacy information on five children who commenced once-daily therapy, but who had incomplete PK data, is given separately (one switched back to twice-daily prior to the second PK day, two had lost samples from one PK day, and two had incomplete sample collection [only 4 and 5 samples were collected on the second PK day]). Six children were recruited but did not commence once-daily therapy and were not followed: two did not attend their first PK day and four had cannulation problems on their first PK day.

Baseline characteristics of the 18 vertically HIV-1-infected children (4, 6 and 8 children in age groups $3-<12,12-<24$ and $24-<36$ months, respectively) with two evaluable PK days are given in Table 1. One child in the $24-<36$ months age group was evaluated for abacavir only (Table 1). Prior to the study, many children had been exposed to two ART classes (7 [39\%] to nucleoside reverse transcriptase inhibitors [NRTIs] and protease inhibitors, and 9 [50\%] to NRTIs and non-nucleoside reverse transcriptase inhibitors). Two (11\%) children had been exposed to all three classes. Sixteen (89\%) children were taking all their ART drugs twice-daily and the remaining two were taking a mixture of twice-daily and once-daily medication (one taking emtricitabine once-daily and one taking nevirapine once-daily).

\section{Pharmacokinetic analyses}

One child, who had a missing $1 \mathrm{~h}$ sample on their first PK day, was excluded from the $\mathrm{C}_{\max }$ analysis (Figure 1). One child missed their $24 \mathrm{~h}$ sample on the second PK day and was excluded from $\mathrm{C}_{\min }$ analysis. Three children vomited post-dose on their second $\mathrm{PK}$ day. One child ( $\mathrm{AUC}_{0-24}$ abacavir 21.54, $\mathrm{AUC}_{0-24}$ lamivudine 7.35, CL/F/kg abacavir 0.72 and CL/ $\mathrm{F} / \mathrm{kg}$ lamivudine 1.06 ) vomited approximately $50-100 \mathrm{ml}$ at $20 \mathrm{~min}$ post-dose; all drugs were given again and the $\mathrm{PK}$ analysis restarted. One child $\left(\mathrm{AUC}_{0-24}\right.$ abacavir 11.20, lamivudine 6.94; $\mathrm{CL} / \mathrm{F} / \mathrm{kg}$ abacavir 1.45 and lamivudine 1.10 ) had a very small vomit 20 min post-dose and drugs were not re-administered. One child ( $\mathrm{AUC}_{0-24}$ abacavir 13.06, lamivudine 5.76; CL/F/kg abacavir 1.23 and lamivudine 1.17 ) vomited approximately $10 \mathrm{ml}$ $1 \mathrm{~h}$ post-dose and drugs were not readministered. All three children were included in all PK analyses.

\section{Abacavir pharmacokinetics}

For the 18 children with evaluable abacavir PK data, median (interquartile range [IQR]) doses were $8.04 \mathrm{mg} / \mathrm{kg}$ (7.74-8.25) for twice-daily and $16.02 \mathrm{mg} / \mathrm{kg}$ (15.53-16.26) for oncedaily. Bioequivalence between twice-daily and once-daily dosing was demonstrated on $\mathrm{AUC}_{0-24}$ (GMR once-daily versus twice-daily, 1.07 [90\% CI 0.92-1.23]) and also for CL/F/ $\mathrm{kg}$ (Table 2 and Figure 2A). GMRs for $\mathrm{AUC}_{0-24}$ and $\mathrm{CL} / \mathrm{F} / \mathrm{kg}$ showed no linear trend with age ( $P=0.6$ for both). The GM of $\mathrm{C}_{\max }$ was approximately double on once-daily compared with twice-daily dosing; there was no difference between age groups $(P=0.3)$.

The GMs of $\mathrm{AUC}_{0-24}, \mathrm{CL} / \mathrm{F} / \mathrm{kg}$ and $\mathrm{C}_{\max }$ on twice-daily and once-daily dosing were comparable with data obtained in children aged 2-13 years (PENTA 13 [17]; Table 2). Slightly higher $\mathrm{AUC}_{0-24}$ and $\mathrm{CL} / \mathrm{F} / \mathrm{kg}$ were observed in children in both the PENTA 13 and 15 studies compared with adults [22].

\section{Lamivudine pharmacokinetics}

For the 17 children with evaluable lamivudine PK data, median (IQR) doses were $4.04 \mathrm{mg}$ / $\mathrm{kg}(3.87-4.13)$ for twice-daily and $8.02 \mathrm{mg} / \mathrm{kg}(7.77-8.13)$ for once-daily. Very similar $\mathrm{AUC}_{0-24}$ values were seen for twice-daily and once-daily dosing of lamivudine (GMR once- 
daily versus twice-daily, 0.91 [90\% CI 0.79-1.06]; Table 3 and Figure 2B), but higher than expected variability resulted in the $90 \% \mathrm{CI}$ falling slightly outside the bioequivalence criteria. Similar results were observed for $\mathrm{CL} / \mathrm{F} / \mathrm{kg}$. As for abacavir, the $\mathrm{GM}$ of $\mathrm{C}_{\max }$ was approximately double on once-daily compared with twice-daily dosing. There were no statistically significant differences among age groups for all $\mathrm{PK}$ parameters $(P=0.2, P=0.3$ and $P=0.1$ for $\mathrm{AUC}_{0-24}, \mathrm{CL} / \mathrm{F} / \mathrm{kg}$ and $\mathrm{C}_{\max }$, respectively).

The GMs of $\mathrm{AUC}_{0-24}, \mathrm{CL} / \mathrm{F} / \mathrm{kg}$ and $\mathrm{C}_{\max }$ on twice-daily and once-daily dosing were comparable with data obtained in children aged 2-13 years (PENTA 13 [17]; Table 3). Additionally, $\mathrm{AUC}_{0-94}$ and $\mathrm{C}_{\max }$ were similar to adult data [23], although the $\mathrm{CL} / \mathrm{F} / \mathrm{kg}$ was slightly higher in children.

\section{Safety and efficacy}

Eighteen children with two evaluable pharmacokinetic days-During the study, no child changed ART regimen and no child discontinued once-daily abacavir (or once-daily lamivudine if applicable) prior to week 12 . One child switched back to twice-daily abacavir and lamivudine at week 16, owing to adherence concerns and fluctuating HIV-1 RNA levels (although at time of switching HIV-1 RNA was $<50$ copies $/ \mathrm{ml}$ and subsequent results were $>50$ copies $/ \mathrm{ml}$ ). Three children, all on zidovudine, abacavir, lamivudine and nevirapine at baseline, discontinued zidovudine during the trial. Three children switched from twice-daily to once-daily nevirapine (one subsequently switched back to twice-daily after therapeutic monitoring) and two children switched to once-daily lopinavir/ritonavir. Overall, 5 (28\%) children experienced a period of taking all their ART medication once-daily during the study.

Virological control was maintained throughout the study. At baseline, 4, 8, 12, 24 and 48 weeks, $89 \%$ (16/18), 93\% (14/15), 93\% (14/15), 94\% (16/17), 100\% (18/18) and 89\% $(16 / 18)$ of children, respectively, had HIV-1 RNA $<400$ copies/ml. Moreover, the proportion of children with HIV-1 RNA $<50$ copies $/ \mathrm{ml}$ remained stable over time. The percentage of $\mathrm{CD}^{+}{ }^{+} \mathrm{T}$-cells also remained stable. Of five children with HIV-1 RNA $\geq 100$ copies $/ \mathrm{ml}$ at screening, three had centralized resistance tests and no major mutations were detected (for the other two children, one sample could not be amplified and one had no stored sample). Six children had HIV-1 RNA $\geq 100$ copies/ml during the first 12 weeks of follow-up and centralized resistance tests were performed on two (three could not be amplified and one had no stored sample), detecting no major mutations.

Four hospitalizations were reported as serious adverse events (one croup, one scalp laceration, one gastroenteritis, one diarrhoea and persistent vomiting [grade 2]); none were judged to be related to ART. Two children had adverse events (one diarrhoea and vomiting of medication [grade 2] and one febrile convulsion). No new CDC B and C events occurred during the study and no child discontinued treatment because of adverse events.

Five children with incomplete pharmacokinetic data-Among five children with incomplete PK data (Figure 1), three were followed until 48 weeks. All three remained on once-daily abacavir and lamivudine and had HIV-1 RNA<400 copies/ml throughout. One child was hospitalized to investigate vomiting and respiratory symptoms; tuberculosis was excluded and vomiting judged probably related to nevirapine. The other two children had limited follow-up data, but in both, vomiting was reported on once-daily abacavir and lamivudine. The first child had severe nausea after commencing once-daily therapy and switched back to twice-daily after 6 days. The second child was hospitalized at week 3 for vomiting with increase of transaminases (aspartate aminotransferase $59 \mathrm{U} / 1$ and alanine aminotransferase $46 \mathrm{U} / \mathrm{l})$. This child remained on once-daily abacavir and lamivudine until 
their second PK assessment (PK data incomplete because of lost samples from first PK day), but then immediately switched back to twice-daily.

\section{Adherence and acceptability}

At baseline, 4 and 12 weeks, 18/18, 18/18 and 16/18 carers, respectively, completed questionnaires. Reported adherence since the last clinical visit on a visual analogue scale ranged between 70\% and 100\%: 71\% (week 0), 80\% (week 4) and 69\% (week 12) recorded $100 \%$ adherence. At week 0 , one child missed a lamivudine dose the day before the PK assessment day and another child missed one abacavir, lamivudine and lopinavir/ritonavir dose 2 days before the PK assessment day. At weeks 4 and 12, no carers reported missed doses over the previous 3 days.

At baseline, all carers thought switching from twice-daily to once-daily would make things easier for them (15/18 [83\%] a lot and 3/18 [17\%] a little). This was supported after the switch to once-daily abacavir/lamivudine, with all carers reporting that the switch had made things easier for them (11/16 [69\%] a lot and 5/16 [31\%] a little). Overall, all carers (apart from one who were unsure) preferred once-daily dosing and 14/16 (88\%) preferred to give the once-daily dose in the morning.

\section{Discussion}

In HIV-1-infected children aged 3-<36 months, bioequivalence was demonstrated on $\mathrm{AUC}_{0-24}$ between twice-daily and once-daily dosing for abacavir; very similar $\mathrm{AUC}_{0-24}$ values were observed for lamivudine, although the $90 \%$ CI for the GMR fell slightly outside the pre-set bioequivalence criteria. As expected, the observed $C_{\max }$ was approximately $2 \times$ higher on once-daily compared with twice-daily therapy for both drugs. Analysis of agerelated differences was limited by the small sample size per age group; however, no consistent trend with age for $\mathrm{AUC}_{0-24}, \mathrm{CL} / \mathrm{F} / \mathrm{kg}$ or $\mathrm{C}_{\max }$ max was seen for either drug.

For abacavir, PK data in children aged 2-13 years (PENTA 13 [17]) were comparable with data in this study. CL/F/kg was higher in children from both studies than in adults (CAL102120 [22]). This might be explained by a difference in the relationship between CL/ $\mathrm{F}$ and weight, as CL/F has been reported to increase linearly with weight in children [25] but exponentially (scaling 0.8) in adults [26]. This could lead to an apparent higher weightnormalized CL/F in children compared with adults. Studies covering a larger age range are required to further evaluate the effect of age and weight on clearance.

For lamivudine, age-dependent CL/F has been widely studied in children and a cutoff for change at approximately 6 years has been reported [27]; lamivudine AUC was reported to be similar in children aged $>6$ years receiving $8 \mathrm{mg} / \mathrm{kg} / \mathrm{day}$ to adults receiving approximately 4 $\mathrm{mg} / \mathrm{kg} /$ day $(300 \mathrm{mg} /$ day), but higher doses $(>8 \mathrm{mg} / \mathrm{kg} /$ day) were required for children $<6$ years to achieve a comparable AUC. In our study, CL/F was comparable to that previously reported $(0.66 \mathrm{l} /[\mathrm{h} \bullet \mathrm{kg}])$ in 59 children with a similar age range: 29 days to 3 years [28]. Further work on a larger dataset is needed to confirm these results because of high variability; however, average $\mathrm{AUC}_{0-24}$ values for lamivudine in PENTA 15 were very similar to those observed in the adult data [23].

We did not measure concentrations of the active intracellular triphosphates of abacavir and lamivudine, as analysis is technically challenging and requires large volumes of blood. Although the correlation between plasma concentration of an NRTI and its intracellular triphosphate is imperfect, it is reasonable to assume that if plasma levels of the parent compound are similar on once-daily and twice-daily dosing then, as in adults [22,23], intracellular levels will also be similar. 
PENTA 15 was designed primarily as a single-arm crossover PK study and so strong conclusions cannot be drawn about efficacy and safety of once-daily use of abacavir and lamivudine. However, we observed no evidence of loss of efficacy over 48 weeks and there were no major safety concerns. Of note, two children with incomplete PK data experienced vomiting shortly after commencing once-daily abacavir and lamivudine, which caused them to switch back to twice-daily. Large volumes of liquids might not be appropriate for all infants.

Virological efficacy results in this study were similar to those observed in children aged 213 years (PENTA 13 [17]); in PENTA 13, during 24 weeks of follow-up no child ( $n=20$ ) discontinued once-daily dosing and similar proportions had undetectable HIV-1 RNA at baseline (16/20 [80\%]) and 24 weeks (17/19 [89\%]). In adults, a trial of 770 participants [15] demonstrated that abacavir once-daily in combination with once-daily lamivudine and efavirenz was non-inferior to abacavir twice-daily: at 48 weeks, $66 \%$ in the once-daily arm compared with $68 \%$ in the twice-daily arm had undetectable HIV-1 RNA. For lamivudine, a trial of 554 adults [16] demonstrated that lamivudine once-daily in combination with zidovudine and efavirenz was equivalent to twice-daily dosing: at 48 weeks, $61 \%$ in the once-daily arm compared with 59\% in the twice-daily arm had undetectable HIV-1 RNA. This has led to once-daily abacavir and lamivudine being a recommended dosing option for these drugs in adults. Data from a substudy of the ARROW trial [29] on 24 Ugandan children aged 3-12 years have recently reported similar $\mathrm{AUC}_{0-24}$ values for twice-daily and once-daily abacavir and lamivudine. Further efficacy and safety data will be available from a planned randomization of several hundred children to receive twice-daily or once-daily dosing of abacavir and lamivudine within the ARROW trial.

Following the results from the CHER trial [30], guidelines recommend [31,32] infants start ART as soon as possible after diagnosis; therefore, children infected vertically with HIV-1 are likely to face lifelong treatment. In this study, good adherence to ART was reported throughout and all carers reported that daily dosing made life easier. Comments included, 'it makes it a lot easier if you're leaving a child with someone else, for example, a childminder', 'will not affect his sleeping any more', 'I will manage to work in the morning', 'tranquillity in the evening' and 'easier to remember'. In PENTA 13 [14], $71 \%$ of carers also reported that once-daily dosing of lamivudine/abacavir made things easier. Although once-daily dosing might be 'less forgiving', if doses are missed this might be offset by better long-term adherence and durability of ART with once-daily dosing, as is now the goal for all therapy in adults.

In conclusion, PENTA 15 showed no major concerns with respect to the pharmacokinetics, efficacy or safety of once-daily dosing of abacavir and lamivudine in children aged 3-<36 months. Data supports findings from the PENTA 13 trial and suggests that carers and children, as well as adults, could benefit from the option of safe, effective and more manageable daily ART regimens. However, at present, individual monitoring of children on once-daily therapy is essential and once-daily versus twice-daily regimens of abacavir and lamivudine should be further explored in large comparative efficacy and safety studies.

\section{Acknowledgments}

We thank all the children, families and staff from the centres participating in the PENTA 15 study.

\section{References}

1. Mocroft A, Ledergerber B, Katlama C, et al. Decline in the AIDS and death rates in the EuroSIDA study: an observational study. Lancet. 2003; 362:22-29. [PubMed: 12853195] 
2. Murphy EL, Collier AC, Kalish LA, et al. Highly active antiretroviral therapy decreases mortality and morbidity in patients with advanced HIV disease. Ann Intern Med. 2001; 135:17-26. [PubMed: $11434728]$

3. Paterson DL, Swindells S, Mohr J, et al. Adherence to protease inhibitor therapy and outcomes in patients with HIV infection. Ann Intern Med. 2000; 133:21-30. [PubMed: 10877736]

4. Chi BH, Cantrell RA, Zulu I, et al. Adherence to first-line antiretroviral therapy affects nonvirologic outcomes among patients on treatment for more than 12 months in Lusaka, Zambia. Int J Epidemiol. 2009; 38:746-756. [PubMed: 19223334]

5. Montaner JS, Reiss P, Cooper D, et al. A randomized, double-blind trial comparing combinations of nevirapine, didanosine, and zidovudine for HIV-infected patients: the INCAS Trial. JAMA. 1998; 279:930-937. [PubMed: 9544767]

6. Gibb DM, Goodall RL, Giacomet V, McGee L, Compagnucci A, Lyall H. Adherence to prescribed antiretroviral therapy in human immunodeficiency virus-infected children in the PENTA 5 trial. Pediatr Infect Dis J. 2003; 22:56-62. [PubMed: 12544410]

7. Pontali E. Facilitating adherence to highly active antiretroviral therapy in children with HIV infection: what are the issues and what can be done? Paediatr Drugs. 2005; 7:137-149. [PubMed: 15977960]

8. Reddington C, Cohen J, Baldillo A, et al. Adherence to medication regimens among children with human immunodeficiency virus infection. Pediatr Infect Dis J. 2000; 19:1148-1153. [PubMed: 11144374]

9. Stone VE, Jordan J, Tolson J, Miller R, Pilon T. Perspectives on adherence and simplicity for HIVinfected patients on antiretroviral therapy: self-report of the relative importance of multiple attributes of highly active antiretroviral therapy (HAART) regimens in predicting adherence. $\mathrm{J}$ Acquir Immune Defic Syndr. 2004; 36:808-816. [PubMed: 15213564]

10. Maitland D, Jackson A, Osorio J, Mandalia S, Gazzard BG, Moyle GJ. Switching from twice-daily abacavir and lamivudine to the once-daily fixed-dose combination tablet of abacavir and lamivudine improves patient adherence and satisfaction with therapy. HIV Med. 2008; 9:667-672. [PubMed: 18631255]

11. Molina JM. Efficacy and safety of once-daily regimens in the treatment of HIV infection. Drugs. 2008; 68:567-578. [PubMed: 18370438]

12. Maggiolo F, Ripamonti D, Arici C, et al. Simpler regimens may enhance adherence to antiretrovirals in HIV-infected patients. HIV Clin Trials. 2002; 3:371-378. [PubMed: 12407486]

13. Portsmouth SD, Osorio J, McCormick K, Gazzard BG, Moyle GJ. Better maintained adherence on switching from twice-daily to once-daily therapy for HIV: a 24-week randomized trial of treatment simplification using stavudine prolonged-release capsules. HIV Med. 2005; 6:185-190. [PubMed: 15876285]

14. LePrevost M, Green H, Flynn J, et al. Adherence and acceptability of once daily lmivudine and abacavir in human immunodeficiency virus type-1 infected children. Pediatr Infect Dis J. 2006; 25:533-537. [PubMed: 16732152]

15. Moyle GJ, Dejesus E, Cahn P, et al. Abacavir once or twice daily combined with once-daily lamivudine and efavirenz for the treatment of antiretroviral-naive HIV-infected adults: results of the Ziagen Once Daily in Antiretroviral Combination Study. J Acquir Immune Defic Syndr. 2005; 38:417-425. [PubMed: 15764958]

16. Dejesus E, McCarty D, Farthing CF, et al. Once-daily versus twice-daily lamivudine, in combination with zidovudine and efavirenz, for the treatment of antiretroviral-naive adults with HIV infection: a randomized equivalence trial. Clin Infect Dis. 2004; 39:411-418. [PubMed: 15307010]

17. Bergshoeff A, Burger D, Verweij C, et al. Plasma pharmacokinetics of once- versus twice-daily lamivudine and abacavir: simplification of combination treatment in HIV-1-infected children (PENTA-13). Antivir Ther. 2005; 10:239-246. [PubMed: 15865218]

18. King JR, Kimberlin DW, Aldrovandi GM, Acosta EP. Antiretroviral pharmacokinetics in the paediatric population: a review. Clin rharmacokinet. 2002; 41:1115-1133.

19. Johnson MA, Moore KH, Yuen GT, Bye A, Pakes GE. Clinical pharmacokinetics of lamivudine. Clin Pharmacokinet. 1999; 36:41-66. [PubMed: 9989342] 
20. Yuen GJ, Weller S, Pakes GE. A review of the pharmacokinetics of abacavir. Clin Pharmacokinet. 2008; 47:351-371. [PubMed: 18479171]

21. Verweij-van Wissen CP, Aarnoutse RE, Burger DM. Simultaneous determination of the HIV nucleoside analogue reverse transcriptase inhibitors lamivudine, didanosine, stavudine, zidovudine and abacavir in human plasma by reversed phase high performance liquid chromatography. $\mathbf{J}$ Chromatogr B Analyt Tecbnol Biomed Life Sci. 2005; 816:121-129.

22. Moyle G, Boffito M, Fletcher C, et al. Steadv-state pharmacokinetics of abacavir in plasma and intracellular carbovir triphosphate following administration of abacavir at 600 milligrams once daily and 300 milligrams twice daily in human immunodeficiency virus-infected subjects. Antimicrob Agents Chemother. 2009; 53:1532-1538. [PubMed: 19188387]

23. Yuen GJ, Lou Y, Bumgarner NF, et al. Equivalent steady-state pharmacokinetics of lamivudine in plasma and lamivudine triphosphate within cells following administration of lamivudine at 300 milligrams once daily and 150 milligrams twice daily. Antimicrob Agents Chemother. 2004; 48:176-182. [PubMed: 14693537]

24. Johnson VA, Brun-Vezinet F, Clotet B, et al. Update of the drug resistance mutations in HIV-1: spring 2008. Top HIV Med. 2008; 16:62-68. [PubMed: 18441382]

25. Jullien V, Urien S, Chappuy H, et al. Abacavir pharmacokinetics in human immunodeficiency virus-infected children ranging in age from 1 month to 16 years: a population analysis. J Clin Pharmacol. 2005; 45:257-264. [PubMed: 15703361]

26. Jullien V, Treluyer JM, Chappuy H, et al. Weight related differences in the pharmacokinetics of abacavir in HIV-infected patients. Br J Clin Pharmacol. 2005; 59:183-188. [PubMed: 15676040]

27. Burger DM, Verweel G, Rakhmanina N, et al. Age-dependent pharmacokinetics of lamivudine in HIV-infected children. Clin Pharmacol Ther. 2007; 81:517-520. [PubMed: 17329994]

28. Tremoulet AH, Capparelli EV, Patel P, et al. Population pharmacokinetics of lamivudine in human immunodeficiency virus-exposed and -infected infants. Antimicrob Agents Chemother. 2007; 51:4297-4302. [PubMed: 17893155]

29. Musiime, V.; Ferrier, A.; Kitaka, SB., et al. Pharmacokinetics of once versus twice daily lamivudine and abacavir in HIV-1 infected Ugandan children in the ARROW trial. 5th IAS Conference on HIV Pathogenesis; Cape Town, South Africa. 19-22 July 2009; Abstract WEPEB271

30. Violari A, Cotton MF, Gibb DM, et al. Early antiretroviral therapy and mortality among HIVinfected infants. N Engl J Med. 2008; 359:2233-2244. [PubMed: 19020325]

31. PENTA Steering Committee. PENTA 2009 guidelines for the use of antiretroviral therapy in paediatric HIV-1 infection. HIV Med. 2009; 10:591-613. [PubMed: 19878352]

32. Working Group on Antiretroviral Therapy and Medical Management of HIV-infected Children. Guidelines for the use of antiretroviral agents in pediatric HIV infection. US Department of Health and Human Services; Updated 23 February 2009Available from http://aidsinfo.nih.gov/ ContentFiles/PediatricGuidelines.pdf [Accessed 17 June 2009] 


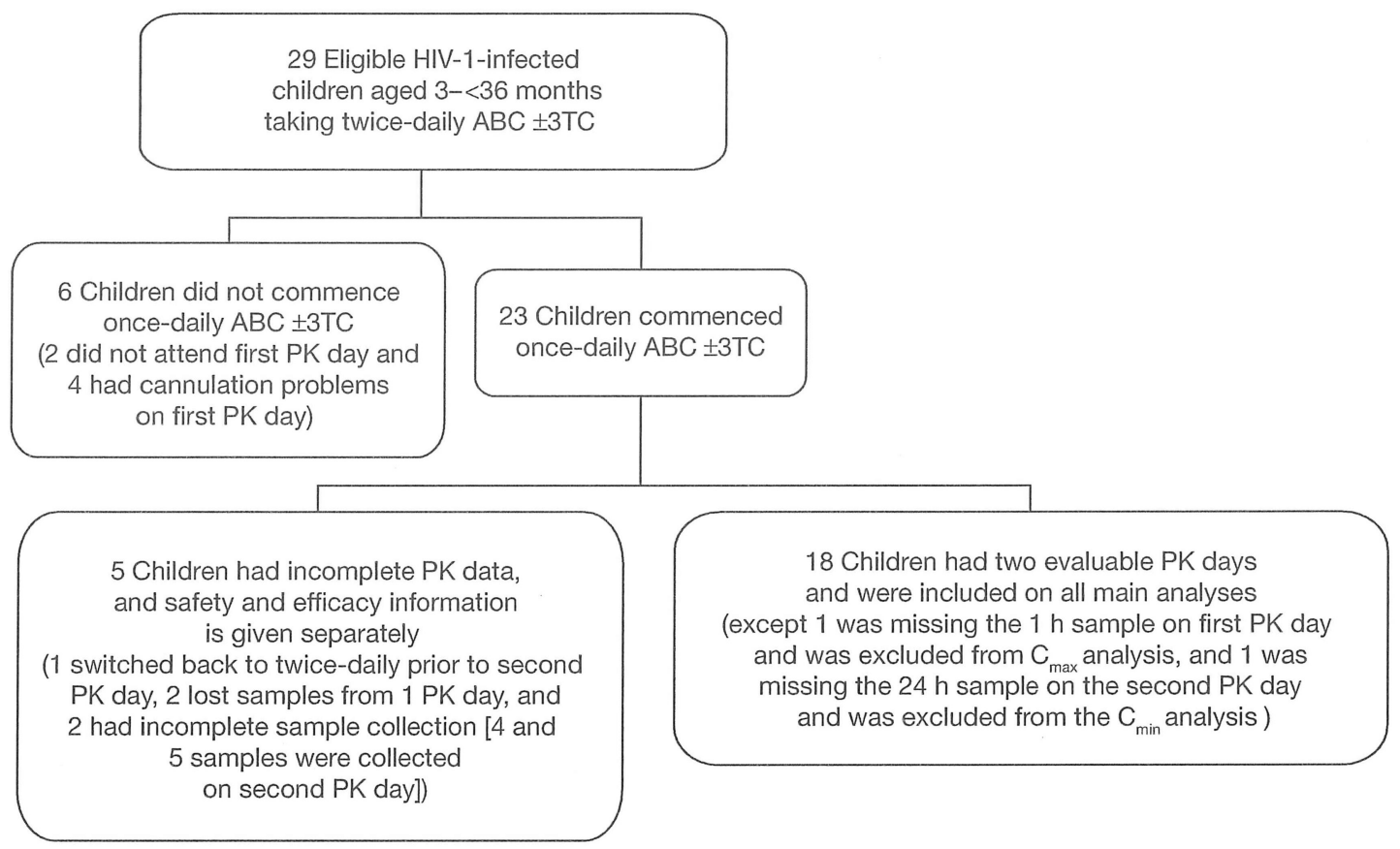

Figure 1.

PENTA 15 participant flow

$\mathrm{ABC}$, abacavir; $\mathrm{C}_{\max }$, maximum plasma concentration; $\mathrm{C}_{\min }$, minimum plasma concentration; HIV-1, HIV type-1; PK, pharmacokinetic; 3TC, lamivudine; \pm , with or without. 
A

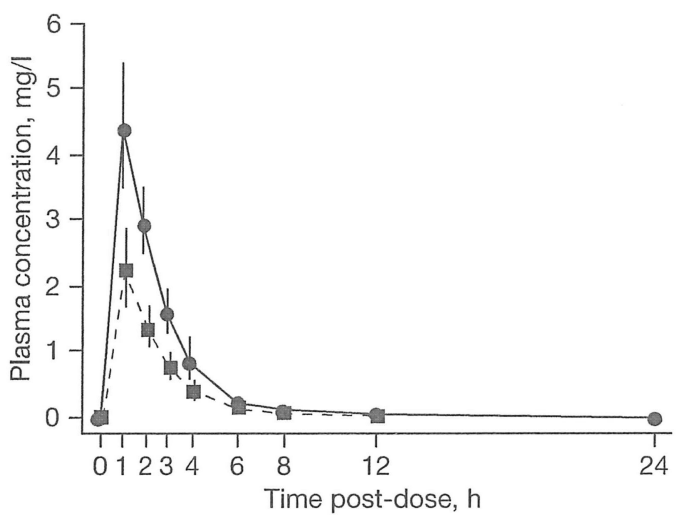

- - - - Twice-daily treatment
B

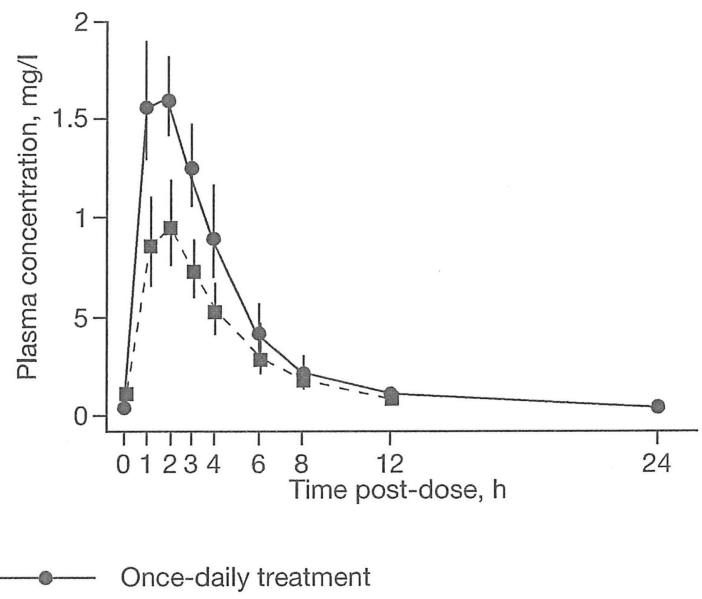

Figure 2.

Geometric mean plasma concentrations with $95 \%$ confidence intervals

Geometric means (95\% confidence interval) of plasma concentrations of (A) abacavir and (B) lamivudine. 
Table 1

Baseline characteristics

\begin{tabular}{ll}
\hline Characteristic & Value \\
\hline Evaluable children, $n(\%)$ & $18(100)$ \\
Median age, months (IQR) & $23.4(12.1-27.8)$ \\
Age range & \\
3-<12 months, $n(\%)$ & $4(22)$ \\
12-<24 months, $n(\%)$ & $6(33)$ \\
24-<36 months, $n(\%)$ & $8(44)$ \\
Gender & \\
Male, $n(\%)$ & $10(56)$ \\
Female, $n(\%)$ & $8(44)$ \\
Median body weight, kg (IQR) & $11.3(10.3-13.0)$ \\
Ethnic origin & \\
White, $n(\%)$ & $3(17)$ \\
Black, $n(\%)$ & $14(78)$ \\
Mixed, $n(\%)$ & $1(6)$ \\
CDC stage & \\
N, $n(\%)$ & $7(39)$ \\
A, $n(\%)$ & $3(17)$ \\
B, $n(\%)$ & $1(6)$ \\
C, $n(\%)$ & $7(39)$ \\
Median cumulative ART exposure, months $(\mathrm{IQR})$ & $11.3(7.4-21.6)$ \\
Antiretroviral therapy combination ${ }^{a}$ & \\
3TC+ABC+NVP $( \pm \mathrm{AZT}$ or $\pm \mathrm{d} 4 \mathrm{~T}), n(\%)$ & $10(56)$ \\
$3 \mathrm{TC}+\mathrm{ABC}+\mathrm{LPV} / \mathrm{r}( \pm \mathrm{AZT}), n(\%)$ & $7(39)$ \\
FTC+ABC+LPV/r, $n(\%)$ & $1(6)$ \\
\hline & \\
&
\end{tabular}

${ }^{a}$ All children were taking all antiretroviral therapy (ART) drugs twice daily, with two exceptions: one child, who was on lamivudine (3TC) and abacavir ( $\mathrm{ABC}$ ), was taking nevirapine (NVP) once daily; and one child on abacavir (ABC) and lopinavir/ritonavir (LPV/r) was taking emtricitabine (FTC) once daily. The child evaluated for $\mathrm{ABC}$ only was $24-<36$ months of age, female, $15.0 \mathrm{~kg}$, White, CDC stage C and taking FTC, ABC plus LPV/r. AZT, zidovudine; d4T, stavudine; IQR, interquartile range. 
Table 2

Abacavir pharmacokinetic parameters

\begin{tabular}{|c|c|c|c|c|c|c|}
\hline PK parameter & $\begin{array}{l}\text { Study } \\
\text { (subdivided by age } \\
\text { group) }\end{array}$ & $\begin{array}{l}\text { Evaluable } \\
\text { patients, } n\end{array}$ & $\begin{array}{l}\text { GM }(95 \% \text { CI }) \\
\text { twice-daily }\end{array}$ & $\begin{array}{l}\text { GM }(95 \% \text { CI) } \\
\text { once-daily }\end{array}$ & $\begin{array}{l}\text { GMR }(90 \% \text { CI }) \\
\text { once-daily versus } \\
\text { twice-daily }\end{array}$ & Reference \\
\hline \multirow[t]{8}{*}{$\mathrm{AUC}_{0-24}, \mathrm{~h} \bullet \mathrm{mg} / \mathrm{l}$} & PENTA 15 & 18 & $10.85(8.89-13.24)$ & $11.57(9.89-13.53)$ & $1.07(0.92-1.23)$ & - \\
\hline & $3-<12$ months & 4 & $12.68(6.52-24.64)$ & $15.90(8.86-28.52)$ & $1.25(1.12-1.41)$ & - \\
\hline & $12-<24$ months & 6 & $13.89(10.40-18.54)$ & $10.60(7.68-14.63)$ & $0.76(0.56-1.05)$ & - \\
\hline & $24-<36$ months & 8 & $8.34(6.27-11.08)$ & $10.53(8.87-12.50)$ & $1.26(1.07-1.48)$ & - \\
\hline & PENTA 13 & 14 & $9.91(8.26-11.89)^{a}$ & $13.37(11.80-15.16)^{a}$ & $1.35(1.19-1.54)$ & {$[17]$} \\
\hline & $2-6$ years & 9 & $9.27(7.06-12.18)^{a}$ & $13.55(11.19-16.42)^{a}$ & - & - \\
\hline & $>6-13$ years & 5 & $11.17(8.76-14.24)^{a}$ & $13.06(10.91-15.63)^{a}$ & - & - \\
\hline & CAL $102120^{b}$ & 27 & $7.90(6.66-9.39)$ & $8.52(7.23-10.04)$ & $1.08(1.02-1.15)$ & [22] \\
\hline \multirow[t]{8}{*}{$\mathrm{CL} / \mathrm{F} / \mathrm{kg}, 1 / \mathrm{h} \bullet \mathrm{kg}$} & PENTA 15 & 18 & $1.47(1.21-1.79)$ & $1.38(1.17-1.62)$ & $0.94(0.81-1.08)$ & - \\
\hline & $3-<12$ months & 4 & $1.23(0.61-2.48)$ & $0.97(0.52-1.81)$ & $0.79(0.71-0.88)$ & - \\
\hline & $12-<24$ months & 6 & $1.17(0.94-1.46)$ & $1.52(1.11-2.09)$ & $1.30(0.97-1.76)$ & - \\
\hline & $24-<36$ months & 8 & $1.91(1.44-2.53)$ & $1.52(1.29-1.78)$ & $0.79(0.66-0.95)$ & - \\
\hline & PENTA 13 & 14 & $1.58(1.30-1.93)^{a}$ & $1.16(1.01-1.34)^{a}$ & $0.73(0.64-0.84)$ & {$[17]$} \\
\hline & $2-6$ years & 9 & $1.80(1.37-2.36)^{a}$ & $1.21(1.00-1.47)^{a}$ & - & - \\
\hline & $>6-13$ years & 5 & $1.26(0.96-1.64)^{a}$ & $1.08(0.81-1.44)^{a}$ & - & - \\
\hline & CAL $102120^{b}$ & 27 & $1.09(0.91-1.29)$ & $1.01(0.86-1.19)$ & $0.93(0.86-1.00)$ & [22] \\
\hline \multirow[t]{8}{*}{$\mathrm{C}_{\max }, \mathrm{mg} / \mathrm{l}$} & PENTA 15 & & $1.38(1.17-1.62)$ & $4.68(3.86-5.67)$ & $2.04(1.73-2.42)$ & - \\
\hline & $3-<12$ months & 4 & $2.43(1.37-4.31)$ & $5.89(2.83-12.26)$ & $2.42(1.64-3.59)$ & - \\
\hline & $12-<24$ months & 6 & $3.18(2.24-4.52)$ & $5.29(3.70-7.56)$ & $1.66(1.12-2.46)$ & - \\
\hline & $24-<36$ months & $7^{c}$ & $1.67(1.10-2.53)$ & $3.69(2.95-4.61)$ & $2.21(1.74-2.80)$ & - \\
\hline & PENTA 13 & 14 & $2.14(1.79-2.56)^{a}$ & $4.80(4.04-5.71)^{a}$ & $2.25(1.83-2.77)$ & {$[17]$} \\
\hline & $2-6$ years & 9 & $1.94(1.50-2.51)^{a}$ & $5.07(3.92-6.56)^{a}$ & - & - \\
\hline & $>6-13$ years & 5 & $2.54(2.00-3.22)^{a}$ & $4.36(3.39-5.60)^{a}$ & - & - \\
\hline & CAL102120 $b$ & 27 & $1.84(1.58-2.15)$ & $3.85(3.34-4.42)$ & $2.09(1.88-2.32)$ & {$[22]$} \\
\hline $\mathrm{C}_{\min }, \mathrm{mg} / \mathrm{l}$ & PENTA 15 & $17^{d}$ & $0.03(<0.015-0.08)^{e}$ & $<0.015(<0.015-0.07)^{e}$ & N/A & - \\
\hline $\mathrm{T}_{1 / 2}, \mathrm{~h}$ & PENTA 15 & 18 & $1.66(0.99-2.95)^{e}$ & $2.15(1.40-4.98)^{e}$ & N/A & - \\
\hline \multicolumn{7}{|c|}{$90 \%$ confidence interval $(\mathrm{CI})$. } \\
\hline \multicolumn{7}{|l|}{$b$ Adult study. } \\
\hline \multicolumn{7}{|c|}{ c One child excluded because of a missing $1 \mathrm{~h}$ plasma concentration on the first pharmacokinetic (PK) sampling day. } \\
\hline \multicolumn{7}{|c|}{$d_{\text {One child excluded because of a missing } 24 \mathrm{~h} \text { plasma concentration on the second PK sampling day. }}$} \\
\hline
\end{tabular}

Antivir Ther. Author manuscript; available in PMC 2013 November 14. 
Table 3

Lamivudine pharmacokinetic parameters

\begin{tabular}{|c|c|c|c|c|c|c|}
\hline PK parameter & $\begin{array}{l}\text { Study } \\
\text { (subdivided by age } \\
\text { group) }\end{array}$ & $\begin{array}{l}\text { Evaluable } \\
\text { patients, } n\end{array}$ & $\begin{array}{l}\text { GM }(95 \% \text { CI }) \\
\text { twice-daily }\end{array}$ & $\begin{array}{l}\text { GM }(95 \% \text { CI) } \\
\text { once-daily }\end{array}$ & $\begin{array}{l}\text { GMR }(90 \% \text { CI }) \\
\text { once-daily versus } \\
\text { twice-daily }\end{array}$ & Reference \\
\hline \multirow[t]{8}{*}{$\mathrm{AUC}_{0-24}, \mathrm{~h} \bullet \mathrm{mg} / \mathrm{l}$} & PENTA 15 & 17 & $9.48(7.89-11.40)$ & $8.66(7.46-10.06)$ & $0.91(0.79-1.06)$ & - \\
\hline & $3-<12$ months & 4 & $9.24(4.66-18.32)$ & $10.31(6.26-16.96)$ & $1.11(0.95-1.31)$ & - \\
\hline & $12-<24$ months & 6 & $9.54(6.71-13.57)$ & $7.13(5.84-8.71)$ & $0.75(0.58-0.96)$ & - \\
\hline & $24-<36$ months & 7 & $9.58(6.65-13.78)$ & $9.27(7.11-12.09)$ & $0.97(0.71-1.32)$ & - \\
\hline & PENTA 13 & 19 & $8.88(7.67-10.28)^{a}$ & $9.80(8.64-11.12)^{a}$ & $1.12(1.03-1.21)$ & [17] \\
\hline & $2-6$ years & 10 & $7.60(6.12-9.45)^{a}$ & $8.80(7.43-10.43)^{a}$ & - & - \\
\hline & $>6-13$ years & 9 & $10.55(8.82-12.63)^{a}$ & $11.04(9.06-3.45)^{a}$ & - & - \\
\hline & $\mathrm{EPV} 1001^{b}$ & 60 & $9.21(8.81-9.63)$ & $8.70(8.28-9.14)$ & $0.94(0.92-0.97)$ & [23] \\
\hline \multirow[t]{8}{*}{$\mathrm{CL} / \mathrm{F} / \mathrm{kg} .1 / \mathrm{h} \bullet \mathrm{kg}$} & PENTA 15 & 17 & $0.79(0.65-0.96)$ & $0.86(0.74-1.01)$ & $1.10(0.95-1.28)$ & - \\
\hline & $3-<12$ months & 4 & $0.79(0.36-1.73)$ & $0.72(0.42-1.26)$ & $0.92(0.73-1.16)$ & - \\
\hline & $12-<24$ months & 6 & $0.80(0.55-1.18)$ & $1.05(0.88-1.25)$ & $1.31(1.00-1.71)$ & - \\
\hline & $24-<36$ months & 7 & $0.77(0.53-1.12)$ & $0.81(0.61-1.07)$ & $1.05(0.77-1.43)$ & - \\
\hline & PENTA 13 & 19 & $0.90(0.78-1.04)^{a}$ & $0.80(0.70-0.92)^{a}$ & $0.89(0.82-0.96)$ & {$[17]$} \\
\hline & $2-6$ years & 10 & $1.09(0.89-1.34)^{a}$ & $0.92(0.78-1.08)^{a}$ & - & - \\
\hline & $>6-13$ years & 9 & $0.73(0.63-0.85)^{a}$ & $0.69(0.55-0.87)^{a}$ & - & - \\
\hline & EPV $1001^{b}$ & 60 & $0.44(0.42-0.47)$ & $0.47(0.44-0.50)$ & $1.06(1.02-1.10)$ & [23] \\
\hline \multirow[t]{8}{*}{$\mathrm{C}_{\max }, \mathrm{mg} / \mathrm{l}$} & PENTA 15 & $16^{c}$ & $1.05(0.88-1.26)$ & $1.87(1.65-2.13)$ & $1.78(1.52-2.09)$ & - \\
\hline & $3-<12$ months & 4 & $1.04(0.76-1.41)$ & $2.37(1.57-3.57)$ & $2.29(1.73-3.01)$ & - \\
\hline & $12-<24$ months & 6 & $1.22(0.82-1.80)$ & $1.71(1.46-2.02)$ & $1.41(1.14-1.74)$ & - \\
\hline & $24-<36$ months & $6^{c}$ & $0.92(0.62-1.35)$ & $1.75(1.39-2.20)$ & $1.91(1.35-2.69)$ & - \\
\hline & PENTA 13 & 19 & $1.11(0.96-1.29)^{a}$ & $2.09(1.80-2.42)^{a}$ & $1.90(1.67-2.16)$ & {$[17]$} \\
\hline & $2-6$ years & 10 & $0.94(0.78-1.13)^{a}$ & $1.72(1.48-1.99)^{a}$ & - & - \\
\hline & $>6-13$ years & 9 & $1.34(1.08-1.67)^{a}$ & $2.59(2.04-3.28)^{a}$ & - & - \\
\hline & $\mathrm{EPV} 1001^{b}$ & 60 & $1.19(1.12-1.26)$ & $1.97(1.84-2.11)$ & $1.66(1.57-1.74)$ & [23] \\
\hline $\mathrm{C}_{\min }, \mathrm{mg} / \mathrm{l}$ & PENTA 15 & $16^{d}$ & $0.08(0.03-0.27)^{e}$ & $0.05(<0.015-0.21)^{e}$ & N/A & - \\
\hline $\mathrm{T}_{1 / 2}, \mathrm{~h}$ & PENTA 15 & 17 & $2.99(2.38-4.54)^{e}$ & $5.35(2.83-13.23)^{e}$ & N/A & - \\
\hline
\end{tabular}

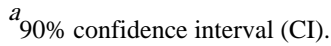

${ }^{b}$ Adult study.

${ }^{c}$ One child excluded because of a missing $1 \mathrm{~h}$ plasma concentration on the first pharmacokinetic (PK) sampling day.

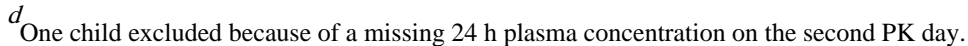

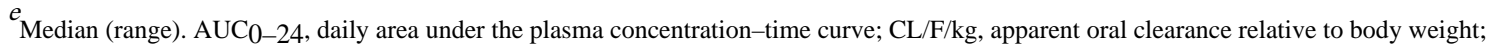
$\mathrm{C}_{\max }$, maximum plasma concentration; $\mathrm{C}_{\min }$, minimum plasma concentration; $\mathrm{GM}$, geometric mean; GMR, geometric mean ratio; N/A, not applicable; $\mathrm{T}_{1 / 2}$, elimination half-life. 